\title{
The Challenges and Opportunities of Dar es - Salaam City Bus Rapid Transit on Implementation and Operations
}

\author{
Nyamatari. A. Tengecha ${ }^{1 *} \quad$ Msabaha Juma Mwendapole ${ }^{2}$ \\ 1.College of Navigation Science, Dalian Maritime University, industrial zone, Liaoning Province, Dalian, China \\ 2.Dalian Maritime University, Transportation and Management College, 116026 No. 1 Linghai Road, Dalian, \\ China
}

\begin{abstract}
Urban traffic congestion is primarily prevalent in large cities caused by city population growth and inefficiency of transportation infrastructure. To minimize the problem, in year 2016, Dar es Salaam city implemented the Dar es Salaam Bus Rapid Transit (BRT) transportation mode. This study introduced to describe the challenges and opportunities of the BRT project to the livelihoods of the city inhabitant. According to the finding, management concerns and regular floods in the main station area are among the project challenges, furthermore, the adoption of the BRT system has typically contributed to the improvement of the urban economy by attracting street seller's around the buses stops, lowering travel times and enhancing access to fundamental society services. The study used a mixed methods approach, which includes both quantitative and qualitative data
\end{abstract}

Keywords: Bus Rapid Transit; transportation; infrastructure

DOI: $10.7176 / \mathrm{DCS} / 11-7-03$

Publication date:July $31^{\text {st }} 2021$

\section{Introduction}

Dar es Salaam- BRT (TRANSIT (DART)) in Tanzania popularly known by local resident as Mwendo-kasi which was launched in May 2016 (Chengula and Kombe, 2017). The city is the most populous in the United Republic of Tanzania, URT and serves as the state economic, commercial, and industrial center. Modal 2014 split analysis, revealed that in every day in and out town movement, Dar es Salaam residents rely heavily on public transportation over other modes of transportation. According to other different studies, roughly 62 percent of individuals in Dar es Salaam (DSM) use public transport (daladala) as their primary method of transportation when moving in and out of the town. The city plans is to have six phase of BRT implemented phases connecting different areas around the region, by 2030, all six phases of the DART system are expected to be completed. The DART system will have a total length of approximately $137 \mathrm{~km}$, and it is intended to serve over 90 percent of the DSM population in Tanzania. Dar es Salaam- BRT is being implemented in order to meet the goals of global development, shortly called MDGs as well as the sustainable goals named as SDGs. The five year development strategic visions of the United Republic of Tanzania since year 2016 as well as 2025 the country's transportation strategy.

The fundamental difficulty for developing megacities in the twenty-first century is that they must meet the needs of transportation connectivity and empower daily income generation while also addressing the negative effects of density on consumers with limited financial resources. With limited and unprepared public transportation, traffic congestion will rise to uncontrolled point in many cities. The walking is the most mean of transportation mode for many dwellers, accounting for more than 70 percentages for example, the Dar es Salaam city (T. Consortium, 2010). While this may epitomize the difficulty of city growth with such low financial resources, there are additional issues, such as widespread corruption, politics, poverty etc. Furthermore, metropolitan institutions are ineffective, property rights are frequently ambiguous and poorly defined. For example, the majority of housing in Nairobi's vital slums is held by landlords who have no legal claim to the land but are powerful political leaders. They not only profit from huge economic rents, but they also obstruct redevelopment and formalization of land (Henderson et al, 2015). All these affect cities planning as a result obstruct the entire urban development process in many African cities.

During implementation and development, Matteo Rizzo engaged in early stage detailed evaluation and BRT negotiations in Dar es Salaam. Specifically, he looked the functionality, coordination and design of the project, It was designed as a public-private partnership and assigned to Dar es Salaam's transportation sector, public to private service delivery (M. Rizzo, 2015). Neo liberal and the divergent opinions of various stakeholder of the project caused significant delays in the realization of the project. Continuing around the need to relocate the bus station location/place, ticket prices, compensation to residents and businesses during development and daladala operators' involvement (city mini-buses owners). These issues, as well as a lack of government support led to operations starting in 2016 rather than the expected 2010s. Rizzo points out that delays execution of the project, were also caused by not only project management failures, but also political negotiation and discussion interaction (M. Rizzo, 2017). The newly launched BRT had already attracted over 200,000 travelers per day in its early days of operation (M. Loyde, 2020). The Dar es Salaam city became the first African metropolitan to 
receive the ITDP's Sustainable Transportation Award in 2018 (ITDP, 2018). Despite the fact that the new transportation system has improved the efficiency of public transit, it is still not fully matched to the needs of many passengers. Furthermore, natural disasters and extreme events, such as sudden floods, pose a significant barrier to the bus system's operation. The BRT bus system has already been disrupted on multiple occasions, causing a considerable number of commuters to lose their daily routines due to different reasons related to buses operations.

\section{Dar es Salaam Project Phases}

The Dar es Salaam city development plans and strategies received amount of fund from World Bank which directed and focused on enhancing urban infrastructure, particularly urban transportation services (African development bank, 2020). The BRT concept was first created by the city council in 2007 after years of discussion, and bus service commenced in 2016. The new transportation network, BRT after its completion will serve roughly a total of one hundred and thirty seven (137) kilometres, and will be built in six phases, as depicted in figure 1 below. This project aims to connect and reach different keys place in the city, such as business center, school, hospital etc. aiming to facilitate transportation in the city by reducing traffic jam, also target to facilitate business around the city. Strabag International $\mathrm{GmbH}$, an Austrian construction company, began work on the first stage in April 2012. In 2022, the second phase is projected to be finished, will connect city center to Mbagala. The third to sixth phases plans have yet to be implemented. There are four BRT lines in operation right now. BRT is planned to connect large areas of DSM-City, however only few are now connected namely, Kimara, Morocco, Kariakoo, Ubungo and Kivukoni. Around the BRT terminals, more parking-lotsstations will be developed. 305 Bus Rapid Transit expected to be deployed and scheduled in the entire operation.

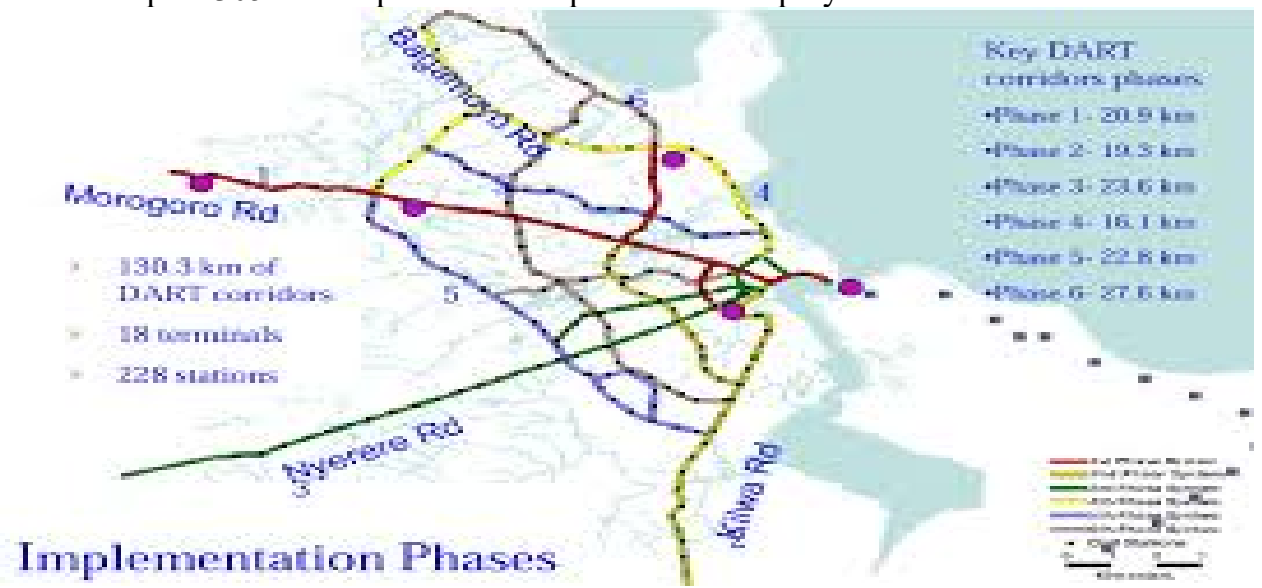

Figure 2.1 DART Phases Network

\section{Dar es Salaam Geographical Location}

Dar es Salaam is a Tanzania business center, located around the coastline of Indian sea. It is one of the major growing mega-cities in sub-Sahara area and in East Africa mostly, the city with current population of over 6.7 million people (Msuya et al, 2019). In, the near future 2030, Dar es Salaam population is expected to be more than ten million people (United nation, 2019). The city, is the main transportation and economic hub in Tanzania and neighbor countries, is where the Tanzania principal port found (Dar es Salaam Port) and used also by land locked countries of DR Congo, Rwanda, Malawi, Burundi, Zambia, Uganda etc. for their goods transportation, import and exports. In this city, urban planning and land matters are mainly frequently challenging issues raise by local residents and authorities. Approximately $70 \%$ of the city's expansion occurs uncontrolled, there is no serious measures taken by government and local people to control the problems (P. Omuga, 2020). Because of the city's population growth, the dependency on public transport is rising too, while transportation infrastructure are limited in DSM city, due to limited financial resources, politics and incompetence administration, since public transport seen as an important mode of transportation and used by many population, therefore is essential to be developed and maintained so that will meet and serve passengers in their daily traveling as a result improve the livelihoods and lifestyles of people. Increasing traffic congestion has become an urgent matter in the city. To reduce the impact of traffic jam and inconvenient mode of transportation network in the city, the BRT operation was finally launched in 2016 by the late Tanzania President HE Dr. John Pombe Magufuli (Rest In Eternal Piece, 1959 - 2021). 


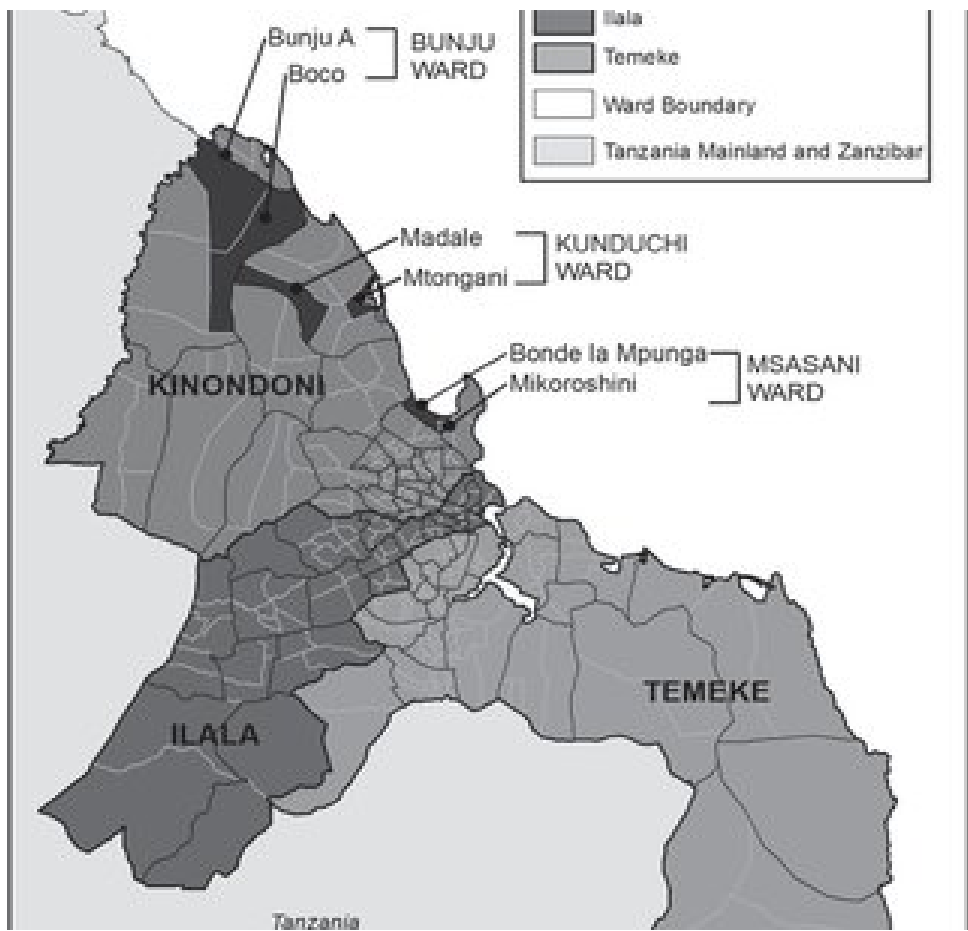

Figure 3.1. Dar es Salaam boundaries and sampled wards and subawards

\section{Research Methodology, Project overview and Findings}

The study employs quantitative and qualitative research methodologies. More specifically, it employed cross sectional survey. The design is suitable for this study because it has measures to gather different types of data from different sources at a particular point in time. The method has possibility to compare and capture the relationship that exists among study variables. Because of this method and the exploratory nature of the study, data was collected mostly through qualitative methods (interviews, mappings, group discussions, documentation and observations). Since the study's purpose was to present a comprehensive picture of BRT-related problems and likelihoods-opportunities. Data connected to activities performed around BRT system were gathered as shown in figure 4.1 . 

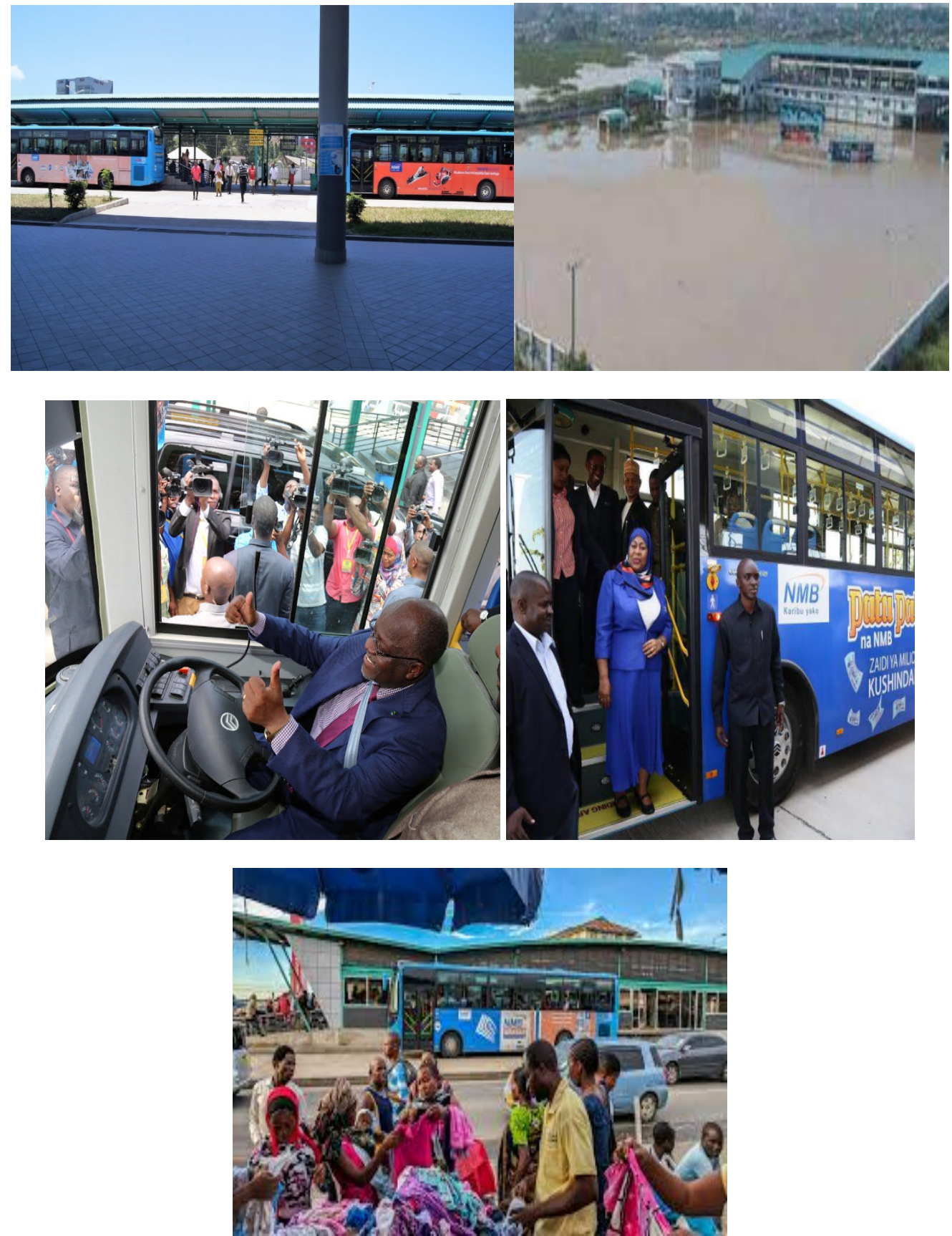

Figure 4.1. Photos representing diverse activities

In this research, semi-structured interview method was used to gather facts associated to DART phase implementation and development. The study involved different groups of respondents, questions were asked to respondents by main researchers through purposive or random sampling technique. Interview times were different scheduled, almost 25 to 30 minutes were used for one respondent and interviewers were divided into several groups to capture their different opinions, experience and reasons learned during and after project implementation, thus respondents categories includes, BRT management, Police (Traffic Police), Dar es Salaam local residents, drivers, DSM city management, government officers etc. as shown in table 1 below. The study assumed, selected categories represent vital clusters with direct or indirect different experienced correlated to BRT system project. 
Table 4.1. Respondent's Category.

\begin{tabular}{|l|l|l|}
\hline Group & Selection technique & Facts gathering tools \\
\hline Tanzania Police Officer & Purposive-sampling technique & Interviews \\
\hline Traffic Management & Purposive -sampling technique & Interviews \& Questionnaires-method \\
\hline Region Authorities & Purposive- sampling technique & Interviews \& Questionnaires-method \\
\hline Daladala/Mini- Bus & Random- sampling technique & Interviews-method \\
\hline Local Street Vendors & Random -sampling technique & Interviews -method \\
\hline Bajaji- Bodaboda Drivers & Random-sampling technique & Interviews-method \\
\hline Dar es Salaam Local Resident & Random -sampling technique & Interviews-method \\
\hline Travelers & Random- sampling technique & Questionnaire-method \\
\hline
\end{tabular}

Various BRT (bus-stops) were plotted during the study of the BRT terminals and bust stops as shown figure 4. The mapping's major goals were to have better understanding of the terminal structure and discover local characteristics in the bus stop environment, such as street vendor and pedestrians. Other public transportation services, such as daladala and bodaboda drivers were pointed. Bus stops like Ubungo, Kariakoo, Kivukoni and Kimara were selected based on their significance within the BRT network. Interviews with different groups of people operating their business near BRT bus stops were conducted, focusing to which extent the BRT implementation and development impacted their business activities and their daily life.

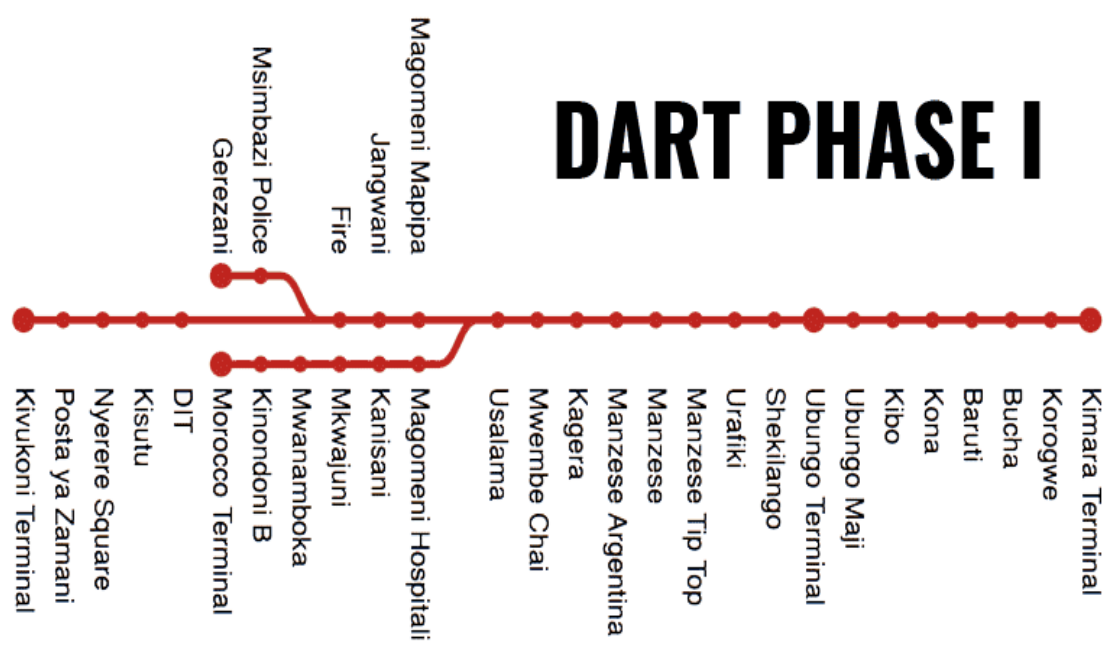

Figure 4.2. BRT phase I

During the survey period, the bus operator like, the private- bus owner association and the bus operator (Dar es Salaam Bus Rapid Trust DART) were interviewed. However due to a lack of service providers to operate the bus, it was unable to be deployed. Initially, a self-owned- buses - service was suggested to control- manage \& operate the BRT- system, but they were unable to achieve the necessary criteria. The bus operation officially, began in 2016. Only 140 out of 305 buses intended are now in service, which can be drastically decreased due to damage caused by several reasons, example floods, mechanical failure, and so on. This causes delays and high demand, particularly during the morning (12 to 9) and (6 to 7) evening hours.

Kimara and Kivukoni bus stops are in high pressure and demand during peak hours as they are key bus system connection, the starting and ending points of the line. As a solution, existing operators are looking for another bus provider that will eventually provide full service. About 3.2 million users in Dar es Salaam use formal and informal transportation daily. It stated that bus rapid transit is become more reliable and the passengers - flow - increasingly, currently, approximately 180,000 people use BRT every day. Around 450 routes available on private buses bring advantage over BRT, which are not always clearly recognized, making them more used in the event of traffic bottlenecks or floods. Though, the DART system plan is considered a modern transportation facility, but has no significant negative impact on private - owned - buses in the city. Flooding caused by rainfall that is excessive is a problem and significant concern for the BRT system. In severe rains, the BRT main connection's Jangwani bridge is frequently swamped, making passage impossible.

Because of the time it saves, the BRT is a core transportation mode, particularly to the residents of isolated urban regions. However, as compared to other modes of public transportation, the transit charge (fare) of 650 Tanzania Shilling (about 0.28 United State Dollar, USD) per journey is not affordable to other users. Finally, low-income individuals opt to walk or take other cheap alternative modes of transportation. Furthermore, the BRT network is not fully developed and customers may need to move a distance looking for service and not all lanes have been developed as high speed lanes. System anomalies were also observed, especially during peak 
hours. It was noted and experienced many criticize from users, lack of smartcard/e-ticket, bus delay and poor customer service from workers, mostly lacking important skills related to their working.

This study found that BRT has good influence on the environment, as it minimize number of vehicles around town, traffic congestion has decreased and traveler flow has improved, resulting in reducing travel time, particularly for individuals reside far from the city center and commute to city center on a daily basis. As a substantial improvement, it has been highlighted, vulnerable groups, such as the elderly, kids, students, children and the disabled, have also benefited, through using this transportation mode. They are mostly at a disadvantage since they are less able to struggle for other transportation modes compared to other transport users groups, BRT have provided easy traveling opportunity to this group. Additionally, BRT systems, it generally considered safe as accidents are significantly reduced on BRT routes and less crimes.

Some challenges were also addressed within BRT operations, such as inadequate service delivery capabilities, the BRT authorities supply limited number of buses that are unable to meet passengers demand, thus, caused by long waiting at bus stops. The deficient is interpreted as a reflection of BRT's profit motive. BRT management should also create parking, particularly for passengers arriving by automobile at the BRT terminal, as well as space for alternative modes of transportation like bajaj and bodaboda. Medical issues have also been raised, as pandemic disease is more prone to occur on overcrowded buses. Construction along the BRT corridor has caused a shift in the urban settlement pattern. The population density rises as more people move into the BRT path. Currently, residential areas are being converted to mixed i.e. residential/business use. The lack of adequate legal and planning tools, as well as insufficient capacities and resources, has resulted in BRT service interruptions. below is table ( $1 \& 2$ ) elaborating BRT- challenges and opportunities.

Table 4.2: Percentage distribution of challenges facing BRT implementation and management.

\begin{tabular}{|c|c|c|c|c|c|c|c|}
\hline Objection & $\begin{array}{l}\text { I (Agree } \\
\text { Strongly ) }\end{array}$ & $\begin{array}{l}\text { II } \\
\text { (Agree) }\end{array}$ & $\begin{array}{l}\text { III } \\
\text { (Neither } \\
\text { Agree/Disagree) }\end{array}$ & $\begin{array}{l}\text { IV } \\
\text { (Dis- } \\
\text { agree) }\end{array}$ & $\begin{array}{l}\text { V } \\
\text { ( Disagree } \\
\text {-Strongly) }\end{array}$ & $\begin{array}{l}\text { VII } \\
\text { (No - } \\
\text { response) }\end{array}$ & OVERALL \\
\hline $\begin{array}{ll}\text { Floods at } \\
\text { Jangwani } \\
\text { station }\end{array}$ & $71.3 \%$ & $24.3 \%$ & - & - & - & $4.4 \%$ & 100.0 \\
\hline $\begin{array}{l}\text { Lack of good } \\
\text { BRT } \\
\text { Management }\end{array}$ & $35.9 \%$ & $51 \%$ & $2.5 \%$ & $10.6 \%$ & - & - & 100.0 \\
\hline $\begin{array}{l}\text { Ticketing } \\
\text { problem }\end{array}$ & $56.3 \%$ & $29.9 \%$ & 13.8 & - & - & - & 100.0 \\
\hline $\begin{array}{l}\text { Long Waiting } \\
\text { time }\end{array}$ & $50.0 \%$ & $26.5 \%$ & $2.9 \%$ & - & - & $20.6 \%$ & 100.0 \\
\hline $\begin{array}{l}\text { Accidents } \\
\text { caused by other } \\
\text { drivers trying } \\
\text { to use BRT }\end{array}$ & $50.0 \%$ & & $23.5 \%$ & - & $14.7 \%$ & $11.8 \%$ & 100.0 \\
\hline $\begin{array}{l}\text { Blocked road } \\
\text { and emergency } \\
\text { vehicles using } \\
\text { BRT lanes }\end{array}$ & $44.1 \%$ & $24.3 \%$ & $5.1 \%$ & $13.2 \%$ & $5.9 \%$ & $7.4 \%$ & 100.0 \\
\hline $\begin{array}{l}\text { Inadequate } \\
\text { road area }\end{array}$ & $55.5 \%$ & $32.3 \%$ & $4.7 \%$ & $5.4 \%$ & $1.9 \%$ & $0.2 \%$ & 100.0 \\
\hline $\begin{array}{l}\text { Limited of road } \\
\text { plan. }\end{array}$ & $76.4 \%$ & $1.9 \%$ & - & $6.8 \%$ & $4.9 \%$ & $10.0 \%$ & 100.0 \\
\hline $\begin{array}{l}\text { High BRT } \\
\text { users demand }\end{array}$ & $13.7 \%$ & $49.6 \%$ & - & $19.8 \%$ & $9.4 \%$ & $7.5 \%$ & 100.0 \\
\hline $\begin{array}{l}\text { Careless } \\
\text { drivers using } \\
\text { BRT lane }\end{array}$ & $46.4 \%$ & $27.5 \%$ & $3.9 \%$ & $2.5 \%$ & $10.8 \%$ & $8.9 \%$ & 100.0 \\
\hline $\begin{array}{l}\text { BRT lane uses } \\
\text { violations by } \\
\text { others. }\end{array}$ & $16.5 \%$ & $13.7 \%$ & $6.9 \%$ & $13.7 \%$ & $34.3 \%$ & $14.9 \%$ & 100.0 \\
\hline
\end{tabular}




\section{Dart-Challenges}
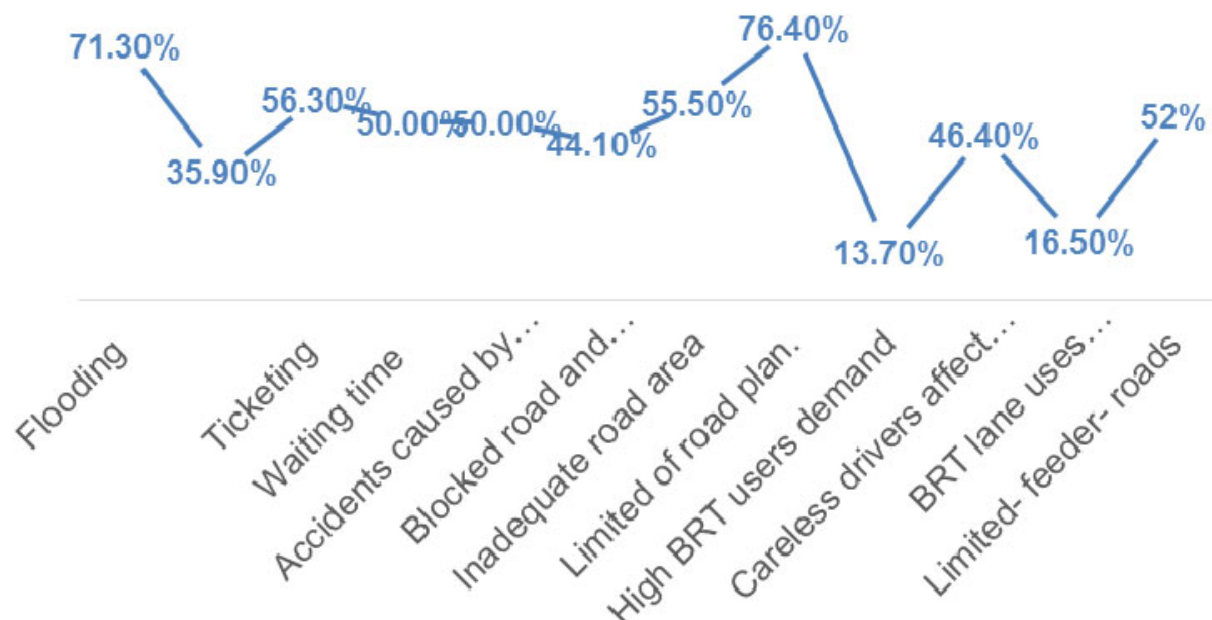

Figure 4.3 Assessing respondent's perception on BRT implementation and management challenges

Table 4.3. Percentage distribution for advantage of BRT implantation

\begin{tabular}{|l|l|l|l|l|l|l|l|}
\hline Benefit & $\begin{array}{l}\text { I } \\
\text { (Agree } \\
\text { Strongly })\end{array}$ & $\begin{array}{l}\text { II } \\
\text { (Agrees) }\end{array}$ & $\begin{array}{l}\text { III } \\
\text { (Neither } \\
\text { Agree/Disagree) }\end{array}$ & $\begin{array}{l}\text { IV } \\
\text { (Dis- } \\
\text { agree) }\end{array}$ & $\begin{array}{l}\text { V } \\
\text { ( Disagree } \\
\text {-Strongly) }\end{array}$ & $\begin{array}{l}\text { VII } \\
\text { (No- } \\
\text { response) }\end{array}$ & OVERALL \\
\hline $\begin{array}{l}\text { Control } \\
\text { traffic-jam }\end{array}$ & $70.8 \%$ & $19.6 \%$ & - & $3.9 \%$ & - & $5.7 \%$ & 100.0 \\
\hline $\begin{array}{l}\text { Tiredness- } \\
\text { Control } \\
\text { resulted by } \\
\text { long-stay- } \\
\text { queuing at } \\
\text { traveling }\end{array}$ & $73.4 \%$ & $23.9 \%$ & -- & - & - & $2.7 \%$ & 100.0 \\
\hline $\begin{array}{l}\text { Increasing } \\
\text { commuting }\end{array}$ & $64.7 \%$ & $29.4 \%$ & $2.9 \%$ & $2.9 \%$ & $8.8 \%$ & $2.9 \%$ & $78.7 \%$ \\
\hline $\begin{array}{l}\text { Vehicle } \\
\text { emissions } \\
\text { reduced }\end{array}$ & $5.9 \%$ & $0.7 \%$ & $2.9 \%$ & - & 100.0 \\
\hline $\begin{array}{l}\text { Improved life } \\
\text { standard for } \\
\text { resident e.g. } \\
\text { street vendor . }\end{array}$ & $14.7 \%$ & $64.7 \%$ & $2.9 \%$ & $8.8 \%$ & $8.8 \%$ & - & 100.0 \\
\hline
\end{tabular}




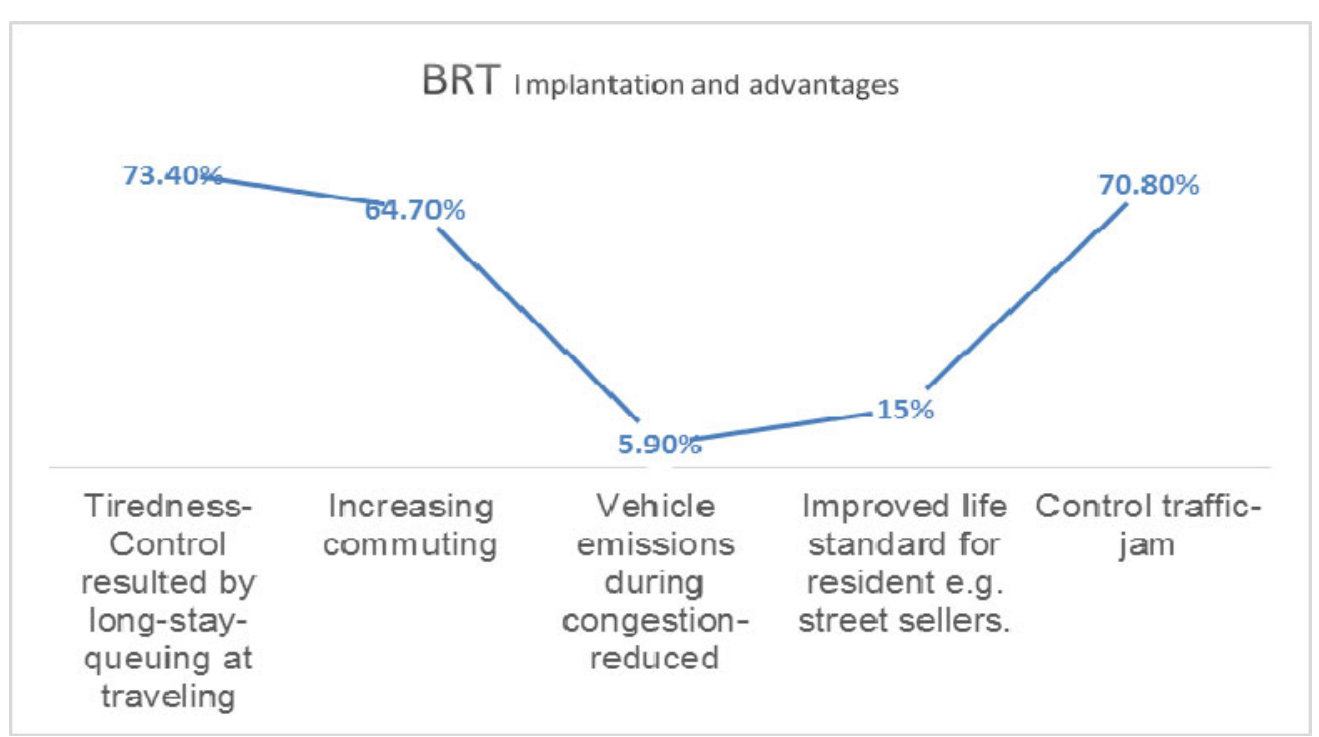

Figure 4.4 Assessing respondent's perception on BRT implantation

Table 4.4 Finding summary of main Challenges and opportunities of the BRT Implementation

\begin{tabular}{|l|l|}
\hline Main Challenges & Percentage Based On Interviewers Perception \\
\hline Flooding at Jangwani bridge & $71.3 \%$ out of $100 \%$ \\
\hline Lack of good BRT Management & $35.9 \%$ \\
\hline Smartcard/E-Ticketing problem & $56.3 \%$ \\
\hline Accidents caused by other drivers trying to use BRT lane & $50.0 \%$ \\
\hline Passengers waiting time at Bus stop & $50.0 \%$ \\
\hline Blocked road and emergency vehicles interfering BRT lanes & $44.1 \%$ \\
\hline Limited- feeder and by pass- roads & $52 \%$ \\
\hline & \\
\hline Opportunities & Percentage based on Interviewers Perception \\
\hline Minimize traffic-jam & $70.8 \%$ \\
\hline Tiredness- control resulted by traveling & $73.4 \%$ \\
\hline Increasing commuting & $64.7 \%$ \\
\hline Vehicle emissions reduced & $5.9 \%$ \\
\hline Improved life standard for resident e.g. street vendor. & $14.7 \%$ \\
\hline
\end{tabular}

\section{Summary, Conclusions and recommendations}

The BRT system has helped to establish numerous new jobs and generate income options for citizens, such as street sellers, improvement in environment protection, while also reducing traffic congestion, particularly along Morogoro road. In and around the city center, travel times are short. When the BRT network is fully operational, it will significantly reduce traffic congestion around the city. The BRT's key obstacles include its sluggish implementation of phases, lack of skilled staffs and administrative issues, politics, among others. By increasing the number of DART-buses, constructing many by-pass and feeder roads will help to meet the high passenger's bus demand and bring relative income progress around the city dwellers. Furthermore, while the BRT offer better travel options for many individuals, it eliminates large group of people due to its relatively high transit expenses, however, the system is not so far open and used by all Dar es Salaam inhabitants. Flooding in the Msimbazi River watershed poses a huge threat to local inhabitants and the BRT system, making service disruption a big concern.

Dependence on the new BRT will grow as subsequent stages are completed, particularly the current implementation of phase II along Kirwa Road, more prospective passengers will be able to use the new BRT service along the Kirwa road towards Mbagala and will connect Pwani region such Mkuranga. Design deficiencies, supervision problems, and such as improper location of the operations center and bus station all like impose hard in daily operation of the bus especially in rain time. Also, this research aided in the strengthening of corporations and the formation of new understanding among BRT stakeholders. The data generated by this study, will be used in the future work. The recommendations are based on the study's findings aim to help policymakers, government, others stakeholders and future scholars that are interested in BRT system topics.

1. The study strongly recommends the need of construction durable keys by-pass and feeder road infrastructure before implementing BRT structure, these will help to maximize transportation network 
capacity and facilitate to minimize the traffic congestion impact.

2. It is recommended that the BRT administration implement smartcards instead of cash ticket. Passengers will use this service whenever it is most inconvenient for them to buy cash tickets in order to avoid overcrowding around ticket selling center.

3. Increasing the effectiveness of law enforcement, this implies, regulations for town traffic- flow management must be enacted in order to promote sustainable transportation growth and traffic congestion control in metropolitan, thus will be more effective by the introduction and implementation of BRT in cities.

4. According to the findings, BRT management should supply more buses in order to reduce overcrowding in bus stations or terminals, especially during peak hours. Many buses on shorter routes that end at should be prioritized.

5. Feasibility study- Related feasibility study should be conducted to get more details of the environment and identify area suitable for constructing and implementing of BRT station and bus stop, this will help to avoid unnecessary challenges rising during daily to daily operation as experienced at Jangwani BRT station area which often fail to operate in rain seasons, as $71.3 \%$ of respondents agree, the Jangwani BRT station is highly affected by flooding.

\section{Future research Work}

The deployment of BRT transportation has the potential to encourage the use of smartcard. More research should be done related in the use of SMARTCARD in BRT.

\section{References}

D. H. Chengula and K. Kombe, "Assessment of the Effectiveness of Dar Es Salaam Bus Rapid Transit (DBRT) System in Tanzania," International Journal of Sciences: Basic and Applied Research, (2017) vol. 36, no. 8, pp. 10-30.

T.-A. Consortium, "Public transport in Sub-Saharan Africa: major trends and case studies," International Association of Public Transport (UITP), Brussels, 2010.

J. V. Henderson, A. J. Venables, T. Regan, and I. Samsonov, "Building functional cities," Science, (2016) vol. 352, no. 6288, pp. 946-947.

M. Rizzo, "The political economy of an urban megaproject: The bus rapid transit project in Tanzania," African Affairs, (2015), vol. 114, no. 455, pp. 249-270

M. Rizzo, Taken for a ride: grounding neoliberalism, precarious labour, and public transport in an African Metropolis. Oxford University Press, 2017.

Loyde, "FactorsInfluencing Urban Public Transport Performance, A Case Study of the Dar Rapid Transit System in Dar EsSalaam, Tanzania," Mzumbe University, 2020.

ITDP, "2018: Dar es Salaam, Tanzania," ITDP, 2018:

A. d. b. group, "African development bank group," July 302020.

G. Todd, I. Msuya, F. Levira, and I. Moshi, "City Profile: Dar es Salaam, Tanzania," Environment and Urbanization ASIA, vol. 10, no. 2, pp. 193-215, 2019.

U. Nations, "The World's cities in 2018," Department of Economic and Social Affairs, Population Division, World Urbanization Prospects, (2018), pp. 1-34,

P. Omunga, "Spatial Planning and Development Strategies in Dar es Salaam City," The Routledge Handbook of Planning Megacities in the Global South, 2020.

\section{Acknowledgment}

Prof. Xinyu Zhang, my academic advisor, has the attitude and substance of a genius, and I wish to express my deepest gratitude to him. Throughout this study, he gave me with tremendous advice, constant support, and assistance. This study would not have been accomplished without his perseverance and meticulous oversight. In addition, I would like to express my gratitude to the Dar es Salaam Bus Rapid Transit Management for their great support, recommendations, critical comments, data and suggestions throughout in this study. Their valuable input helped to improve the quality of this research. Furthermore, I like to express my gratitude to the Tanzania Police Force (Dar es Salaam Traffic Police) for providing data for this study. Also, I want to thank the School of Transport and Logistics, Southwest Jiaotong University (SWJTU) for exposing me to all facets of transportation engineering. Finally, I want to express my gratitude to my family for their unwavering moral support and encouragement throughout this study. 